\title{
Gamma movement: Field brightness, series, and side of the standard'
}

\author{
John J. Winters, Jr. and Irma R. Gerjuoy \\ JOHNSTONE TRAINING AND RESEARCH CENTER, BORDENTOWN, N. J.
}

\begin{abstract}
Abstraet
Gamma movement was investigated under six brightness levels. Comparison circles equal to, and slightly smaller than, the standard were judged "larger" significantly more often than chance. Brightness level did not affect this phenomenon; the effect was more pronounced during the first series and when comparison figures were on the right.
\end{abstract}

\section{Problem}

Gamma movement, the apparent expansion and contraction of a briefly exposed figure, has been investigated recently with normal adults and with retarded children (Winters, 1964, 1965). In these studies, a standard circle was presented in one half of the visual field, followed by the introduction of a comparison circle into the previously darkened half of the field. Offset of the two figures was simultaneous. Normal adults reported the comparison circle as larger when it was objectively the same size or even slightly smaller; retardates showed no such consistency.

Investigators of such phenomena as distance judgment and shape and size constancies have studied the effect of brightness. However, only one gamma study (Bartley, 1936) has included any variation of brightness. By utilizing several concentric densities within a single disc, from dark at the center to bright at the perimeter, Bartley was able to eliminate gamma.

The purposes of the present experiment were to measure the effect of brightness on gamma and to compare the amount of gamma under the conditions of Winters' $(1964,1965)$ previous studies with the amount of gamma when the comparison circle is introduced into a lighted field. It was expected that amount of gamma would vary directly with the brightness of the visual field. The effects of series (first vs. second) and of side of the standard (left vs. right) were also investigated.

\section{Method}

Ss were 60 high school seniors. Five males and five females were randomly assigned to each of six brightness conditions. All Ss who used glasses were required to wear them. Ten day-camp counselors of the same age were used to replicate one treatment.

A modified Gerbrands tachistiscope with two exposure fields was used, with S $79 \mathrm{~cm}$ from the stimuli. Twenty one in front of $\mathrm{S}$ was a slit in which one of five exposed $x$-ray films of different densities could be inserted to attenuate the viewing field. No film was inserted for one treatment. The brightness of each filter was measured by three observers with a Macbeth Illuminometer under the experimental conditions. Table
Table 1. Photometric and Densitometer Values

$\begin{array}{llccccc}\text { Filter Condition } & \text { None } & \text { A } & \text { B } & \text { C } & \text { D } & \text { E } \\ \text { Foot-candles } & 2.38 & 2.29 & 1.03 & 0.26 & 0.15 & 0.01 \\ \text { Densitometer } & --- & 0.0 & 0.30 & 0.60 & 0.90 & 1.60\end{array}$

1 shows the mean measurements in foot-candles and the densitometer standard ${ }^{2}$ for each condition.

Stimuli were two sets of 12 white cards which could be inserted manually into both exposure fields. One set had a master card with a standard circle, $40 \mathrm{~mm}$ in diameter, centered $3.5 \mathrm{~cm}$ left of a central fixation mark; the other set had a master card with an identical standard circle, centered $3.5 \mathrm{~cm}$ right of a fixation mark.

The other 11 cards in each set had a standard circle on one side of a fixation mark, corresponding to the master, and a comparison circle on the other. The centers of the latter circles were $3.5 \mathrm{~cm}$ to the other side of the fixation mark. Of these 11 cards, nine had comparison circles that varied in diameter from 36-44 $\mathrm{mm}$ in increments of $1 \mathrm{~mm}$. The other two cards had comparison circles with diameters of 32 and $48 \mathrm{~mm}$, each of which was used as a training item and as a "lie" item. All figures were drawn in India ink with lines $.5 \mathrm{~mm}$ in width.

Procedure

After S was dark adapted for $10 \mathrm{~min} .$, he was instructed to fixate on the center mark and to report whether the second circle (the comparison figure) was larger or smaller than the first circle (the standard figure).

For each trial, the master card, consisting of the standard circle and the fixation mark, was exposed for $.8 \mathrm{sec}$. Then the comparison card, consisting of the standard circle, fixation mark, and comparison circle, was exposed for $.2 \mathrm{sec}$. Consequently, the standard circle and fixation mark were exposed for 1 sec. and the comparison circle was exposed for the final .2 sec. Intertrial interval was $20 \mathrm{sec}$.

To familiarize $\mathrm{S}$ with the procedure, two training figures were each presented twice with the standard on the same side as in the initial test series. The figures were randomly presented by the method of constant stimuli. Nine of the 11 comparison figures were presented once each and, to increase the reliability of the critical judgments, comparison figures, of 39 and $40 \mathrm{~mm}$ diameter, were presented twice in each series.

After the initial series of 13 trials, $S$ was informed that the standard circle would henceforth appear on the other side of the fixation mark. Each S made 26 judg- 
ments under one of the six brightness conditions. The side on which the standard was initially presented was counterbalanced within each brightness condition.

Following the experimental procedure, eye dominance of each $S$ was measured by the hole-in-card test (Harris, 1958)。

\section{Results}

The data analyzed were the frequencies of "larger" judgments of the comparison figure. The overall number of "larger" judgments, disregarding brightness level, differed significantly from chance $\left(\mathrm{X}^{2}=201 ; \mathrm{p}<.001\right)$. An analysis of variance was performed comparing the number of "larger" judgments of the six brightness groups. A significant effect of brightness level was found, F $(5,48)=4.49 ; \mathrm{p}<.01$. However, only Group C differed significantly from the other five groups in giving fewer "larger" judgments. Since there was neither an experimental nor a psychological reason to expect this group to differ from the others, and particularly since it was expected that the number of "larger" judgments would be a monotonic function of brightness, it was suspected that some chance assignment of Ss to groups accounted for this difference. Consequently, 10 additional Ss were run in a replication of this treatment. All further analyses are reported with the "replication group" ", Group $\mathrm{C}_{\mathrm{R}}$, substituted for the original Group C.

An analysis of variance was performed to compare the six Brightness groups, the Side on which the standard appeared (left vs. right), and the Series of stimulus presentations (first vs. second). The only significant effects were Side of the standard (more "larger" judgments when the standard was on the left, $\mathrm{F}(1,48)=7.97 ; \mathrm{p}<.01$ ) and Series (more "larger" judgments during the first series than during the second series, $F(1,48)=7.18 ; p<.025)$. With the standard on the left, the number of "larger" judgments of the comparison figure above chance was 90 during the first series and 68 during the second. When the standard was on the right, the comparable numbers were 69 and 52.

The frequencies of "larger" judgments on each side were compared for Ss with a right-eye preference vs. Ss with a left-eye preference in a fourfold table. The obtained $\mathrm{X}^{2}$ of .76 was not significant.

\section{Discussion}

Gamma was elicited under all six brightness conditions. The observed frequencies of "larger" and "smaller" judgments differed from their expected values in favor of more "larger" judgments. These results are comparable to those of a previous study which utilized the same procedure but different stimulus conditions (Winters, 1964). It is clear that gamma is perceived to the same extent whether the comparison figure is exposed into the dark half of the field or into an existing field of light.

The results indicate that when $\mathrm{S}$ is dark adapted, only the excitation of retinal cells (not the relative level of brightness) is important for gamma to occur. This is unlike the case of shape or size constancy, where performance on the task seems to depend upon visual acuity and pre-experimental experience, and where changes in brightness do affect Ss' judgments. Following Sptiz's (1964) classification of illusions, into experiential and physiological categories, it is possible that other visual phenomena may be dichotomized into these categories on the basis of the effect of brightness upon them.

More "larger" responses were given for the first series than for the second. This decrease in gamma over time might be due to a satiation effect [depression of the affected visual area after the prolonged presence of a given figure (Köhler \& Wallach, 1944)], a decrease of attention over time, or a tendency to balance the number of "larger" and "smaller" judgments following a number of "larger" judgments.

Although gamma occurred whether the comparison circle appeared on the left or right, this phenomenon was more pronounced when the comparison figure was on the right. This side preference was not related to ocular dominance as suggest by Coules (1955) in a study of distance judgments.

To investigate the generality of right-side preference for geometric figures, the same Ss were given a second task one week later. Each $\mathrm{S}$ was presented 10 cards, with two identical figures (circles, squares, hexagons, or triangles) symmetrically placed. S's self-paced task was to indicate whether the left or right figure was larger. There was a strong right-side preference $\left(X^{2}=20.5\right.$; $p<.001)$. Similar results have been obtained by Gerjuoy et al (1964) in a probability learning study and by Iwahara (1959) in an alternation study. While there is little doubt that gamma movement is physiological, these experiential components may enhance or minimize the effect.

References

BARTLEY, S. H. The relation of retinal illumination to the experience of movement. J. exp. Psychol., 1936, 19, 475-485.

COULES, J. Effect of photometric brightness on judgments of distance. J. exp. Psychol., 1955, 50, 19-25.

GERJUOY, I。 R。, GERJUOY, H., \& MATHIAS, R. Probability learning: Left-right variables and response latency. J. exp. Psychol., 1964, $68,344-350$.

HARRIS, A. J. Harris tests of lateral dominace: Manual of directions for administration and interpretation. (3rd ed.) New York: Psychological Corporation, 1958.

IWAHARA, S. Studies in spontaneous alternation in human subjects: III. A developmental study. Jap. psychol. Res., 1959, 1, 1-8. KÖHLER, W., \& WALLACH, H. Figural after-effects; an investigation of visual processes. Proc. Amer. Phil: Soc., 1944, 88, 269-357.

SPITZ, $H_{\circ} H_{0}$ A comparison of mental retardates and normals on the rotating trapezoidal window illusion. J. abnorm. soc. Psychol., $1964,68,574-578$.

WINTERS, J. J., JR.Gamma movement: Apparent movement in figural after-effects experiments. Percept. mot. Skills, 1964, 19, 819-822. WINTERS, J. J., JR. Gamma movement: A comparison of normals and retardates. Amer. J. ment. Defic., 1965, in press.

Notes

1. The authors express appreciation to Joseph Conerton, and Robert Bice of Bordentown High School and to Zev Hymowitz, of the Trenton Jewish Community Center, for their aid and cooperation. The authors also thank Peter L. Carlton, Sydell T. Carlton, Herbert Gerjuoy, David L. Hoats and Herman H. Spitz for their critical reading of the manuscript.

2. Measured by William Bauers on a Picker Densitometer. 